\title{
Erratum
}

\section{Erratum to "Bubble Bursting and Drainage Characteristics at the Free Surface of a Liquid Pool with an Aerosol"}

\author{
Xiang Yu $\left(\mathbb{D}\right.$, Haifeng Gu $\mathbb{D}^{D}$, Weikai Yin $\mathbb{D}^{D}$, and Qingyang Sun \\ Heilongjiang Provincial Key Laboratory of Nuclear Power System \& Equipment, Harbin Engineering University, \\ Harbin 150001, China \\ Correspondence should be addressed to Haifeng Gu; guhaifeng1980@163.com
}

Received 29 March 2021; Accepted 29 March 2021; Published 10 April 2021

Copyright (c) 2021 Xiang Yu et al. This is an open access article distributed under the Creative Commons Attribution License, which permits unrestricted use, distribution, and reproduction in any medium, provided the original work is properly cited.

In the article titled "Bubble Bursting and Drainage Characteristics at the Free Surface of a Liquid Pool with an Aerosol" [1], the authors were affiliated to "Heilongjiang Provincial Key Laboratory of Nuclear Power System \& Equipment, Harbin 150001, China," which is incorrect.

The correct affiliation for the authors is "Heilongjiang Provincial Key Laboratory of Nuclear Power System \& Equipment, Harbin Engineering University, Harbin 150001, China." The correct affiliation is shown in the author information above.

This mistake occurred during the production of the article, and the publisher apologises for this error.

\section{References}

[1] Y. Xiang, H. Gu, W. Yin, and Q. Sun, "Bubble bursting and drainage characteristics at the free Surface of a liquid pool with an aerosol," Science and Technology of Nuclear Installations, vol. 2020, Article ID 8829074, 13 pages, 2020. 